\title{
Disease Severity and Motor Impairment Correlate With Health-Related Quality of Life in AP-4-Associated Hereditary Spastic Paraplegia
}

Catherine Jordan, BA,* Gregory Geisel, BS,* Julian E. Alecu, cand. med., Bo Zhang, PhD, Mustafa Sahin, MD, PhD, and Darius Ebrahimi-Fakhari, MD, PhD

Neurol Genet 2021;7:e605. doi:10.1212/NXG.0000000000000605
Correspondence

Dr. Ebrahimi-Fakhari

darius.ebrahimi-fakhari@

childrens.harvard.edu

\section{Abstract}

\section{Objective}

AP-4-associated hereditary spastic paraplegia (AP-4-HSP) is a childhood-onset neurogenetic disease and mimic of cerebral palsy. Data on health-related quality of life (HRQoL) are lacking. To establish a metric for HRQoL and caregiver priorities, we used the Caregiver Priorities and Child Health Index of Life with Disabilities (CPCHILD) questionnaire to assess HRQoL in correlation with disease severity in 64 patients with AP-4-HSP.

\section{Methods}

A cross-sectional analysis of caregiver-reported HRQoL was performed using the CPCHILD questionnaire in combination with a detailed clinical characterization.

\section{Results}

HRQoL was impaired in all domains in patients with AP-4-HSP (mean score: $59.6 \pm 12.6$ [SD]), with no significant difference between the 4 subtypes. Age, as a surrogate for disease duration, and Spastic Paraplegia Rating Scale scores, as an indicator for corticospinal tract dysfunction and motor impairment, correlated with lower CPCHILD scores (Pearson $r=$ $-0.31, p=0.01$ and $r=-0.52, p<0.0001$, respectively). Patients with tetraplegia showed lower CPCHILD scores compared with individuals with diplegia or no spasticity. Wheelchair dependence reduced HRQoL in all domains. The presence of seizures, including medically refractory epilepsy, was not associated with lower CPCHILD scores. Standardized assessment of caregiver priorities identified several areas of high importance to HRQoL.

\section{Conclusions}

We show that the CPCHILD questionnaire, developed for use in children with cerebral palsy, can be used to assess HRQoL in patients with childhood-onset complex hereditary spastic paraplegia. HRQoL is reduced in patients with AP-4-HSP and correlates with the degree of motor impairment. These results provide a framework for medical decision making and a baseline for the future development of treatment guidelines and interventional trials.

\footnotetext{
*These authors contributed equally to this work as co-first authors.
}

From the Department of Neurology and The F.M. Kirby Neurobiology Center (C.J., G.G., J.E.A., M.S., D.E.-F.), Rosamund Stone Zander Translational Neuroscience Center (G.G., M.S.), and ICCTR Biostatistics and Research Design Center (B.Z.), Boston Children's Hospital, Harvard Medical School, MA. 


\section{Glossary}

4FMS = 4-stage functional mobility scale; AP-4-HSP = AP-4-associated hereditary spastic paraplegia; CPCHILD = Caregiver Priorities and Child Health Index of Life with Disabilities; HRQoL = health-related quality of life; SPRS = Spastic Paraplegia Rating Scale.

Biallelic mutations in genes encoding the subunits of the AP-4 complex (AP4B1, AP4M1, AP4E1, and AP4S1) lead to childhood-onset and complex hereditary spastic paraplegia (SPG47, SPG50, SPG51, and SPG52). ${ }^{1,2}$ Not unlike in cerebral palsy, motor symptoms in AP-4-associated hereditary spastic paraplegia (AP-4-HSP) are accompanied by global developmental delay and intellectual disability, seizures, and secondary musculoskeletal problems. ${ }^{1-3}$ All patients with AP-4-HSP experience difficulties with their activities of daily living, communication, and mobility and depend on their caregivers for most of their needs. The morbidity that arises from progressive motor symptoms has a significant effect on families. Symptomatic treatment of spasticity, contractures, or seizures is aimed at preventing or relieving discomfort and at enabling optimal development and quality of life. ${ }^{1}$ In this setting, it is important to establish a metric for health-related quality of life (HRQoL) and to understand caregiver perspectives. Such a metric can inform shared medical decisionmaking and the development of treatment guidelines. HRQoL measures are complementary to the assessment of clinical disease severity, and it is important to establish if correlation exists. Such correlation would have implications for the choice of clinical rating scales in longitudinal natural history studies and interventional trials. To approximate HRQoL in AP-4-HSP, we used the revised Caregiver Priorities and Child Health Index of Life with Disabilities (CPCHILD) questionnaire in 64 individuals with AP-4-HSP and investigated correlations with major symptoms and disease severity.

\section{Methods}

\section{Standard Protocol Approvals, Registrations, and Patient Consents}

This study was approved by the institutional review board at Boston Children's Hospital (No. IRB-P00033016). Written consent was obtained.

\section{Data Collection and Statistical Analysis}

Primary caregivers of 64 patients with genetically confirmed AP-4-HSP were asked to complete the CPCHILD questionnaire ${ }^{4}$ (eMethods, links.lww.com/NXG/A440). Spastic Paraplegia Rating Scale (SPRS) total and spasticity subscores ${ }^{5,6}$ and the 4-stage functional mobility scale (4FMS) were assigned as described previously ${ }^{2}$ (eMethods). Statistical analysis was performed with GraphPad Prism v9.0 and IBM SPSS v27. Unpaired $t$ test or one-way analysis of variance with multiple comparisons was used to determine the significance of differences between conditions. Linear regression analysis and
Table Summary of Demographic Information and Clinical Scores

\begin{tabular}{ll}
\hline Patients with AP-4-HSP $(\mathbf{n}=\mathbf{6 4}), \mathbf{n}(\%)$ & $30(46.9)$ \\
\hline Female & $31(48.4)$ \\
\hline SPG47 (AP4B1) & $21(32.8)$ \\
\hline SPG50 (AP4M1) & $2(3.1)$ \\
\hline SPG51 (AP4E1) & $10(15.6)$ \\
\hline SPG52 (AP4S1)
\end{tabular}

Age, $y(n=64)$

\begin{tabular}{ll}
\hline Mean \pm SD & $12.45 \pm 10.53$ \\
\hline \multicolumn{1}{c}{ Range } & $1.45-49.52$ \\
\hline Consanguinity $(\mathbf{n}=\mathbf{6 4}), \mathbf{n}(\%)$ & $15(23.4)$ \\
\hline $\begin{array}{l}\text { More than 1 affected family member }(\mathbf{n}=\mathbf{6 4}), \\
\mathbf{n}(\%)\end{array}$ & $24(37.5)$ \\
\hline
\end{tabular}

Severity of intellectual disability $(n=64), n(\%)$

\begin{tabular}{ll}
\hline Severe & $24(37.5)$ \\
\hline Moderate & $20(31.3)$ \\
\hline Mild & $7(10.9)$ \\
\hline Too young or information not available & $13(20.3)$ \\
\hline SPRS (total score) $(\mathbf{n}=\mathbf{5 1})$ & $30.2 \pm 10.8$ \\
\hline Mean \pm SD & $0-52$ \\
\hline Range & $7.2 \pm 3.6$ \\
\hline SPRS (spasticity subscore) $(\mathbf{n}=\mathbf{5 1})$ & $0-16$ \\
\hline Mean \pm SD & $1(1.6)$ \\
\hline Range & $9(14.5)$ \\
\hline 4FMS ( $\mathbf{~ = ~ 6 2 ) , ~} \mathbf{~ ( \% )}$ & $26(41.9)$ \\
\hline I & $26(41.9)$ \\
\hline II & \\
\hline III & \\
\hline IV & \\
\hline
\end{tabular}

Developmental support $(n=64), n(\%)$

\begin{tabular}{ll}
\hline Physical therapy & $42(65.6)$ \\
\hline Occupational therapy & $34(53.1)$ \\
\hline Speech therapy & $39(60.9)$ \\
\hline
\end{tabular}

Abbreviations: 4FMS = 4-stage functional mobility scale; AP-4-HSP = AP-4-associated hereditary spastic paraplegia; SPRS = Spastic Paraplegia Rating Scale. 
Pearson correlation coefficient were used to determine statistical correlation. The Spearman rank correction coefficient was used to ensure a monotonic relationship.

\section{Data Availability}

Data are available from the corresponding author on reasonable request.

\section{Results}

Demographic and clinical characteristics of the study cohort are summarized in Table. The most common subtype of AP4-HSP was AP4B1-associated SPG47, comparable with the general prevalence of this subtype. ${ }^{1,2}$ The mean age was $12.5 \pm$ 10.5 (SD) years (range 1.5-49.5 years). Most families resided in Europe, North America, and the Middle East. Approximately $38 \%$ of participating families had more than 1 affected child. The mean SPRS score was $30.2 \pm 10.8$ (SD) consistent with a moderate degree of corticospinal tract dysfunction. The distribution of the 4FMS indicated that the majority of patients requires assistance with ambulation $(4 \mathrm{FMS}=3)$ or are wheelchair-dependent (4FMS = 4) (Table). The standardized CPCHILD score showed an even distribution between subsections (Figure 1A). The mean total score was $59.6 \pm$
12.6 (SD) with no significant difference between the 4 AP-4HSP subtypes (Figure 1B) or between male and female patients (Figure 1C). All patients had access to special education programs, and supportive therapy was provided to the majority of patients at the time of evaluation (Table).

Based on evidence derived from studies in children with cerebral palsy, ${ }^{4,7}$ we hypothesized that patients with severe AP4-HSP disease would have lower HRQoL. We found that age, as a surrogate for disease duration, and SPRS scores correlated with lower CPCHILD scores (Figure 1, D and E). The spasticity subscore of the SPRS showed a moderate correlation as well, indicating that severity of motor symptoms and resulting disability contribute to HRQoL (Figure 1F). This was further corroborated by significantly lower CPCHILD scores in patients with tetraplegia compared with individuals with diplegia or no spasticity (Figure $1 G$ ). Based on this finding, we hypothesized that HRQoL for nonambulatory patients would be worse than for ambulatory patients. Indeed, a significantly lower mean CPCHILD score was found in wheelchair-dependent patients (Figure 2A). To assess whether this was the result of impaired $\mathrm{QoL}$ related to positioning, transferring, and mobility (section 2), we compared

Figure 1 Disease Severity and Motor Impairment Correlate With Health-Related Quality of Life in 64 Patients With AP-4-HSP

A

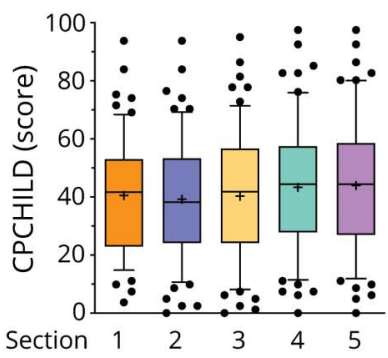

$\mathrm{E}$

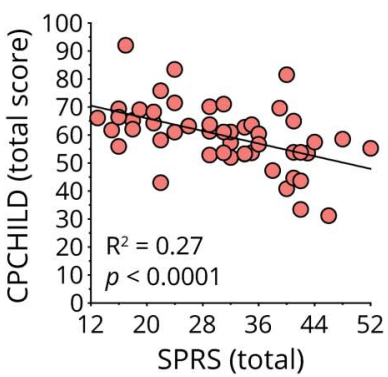

B

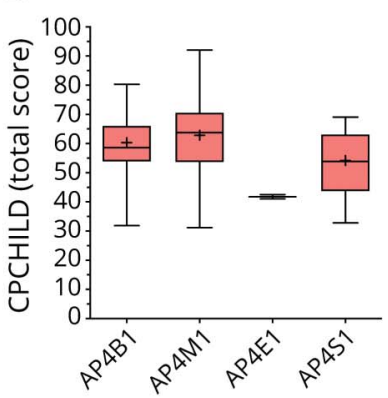

F

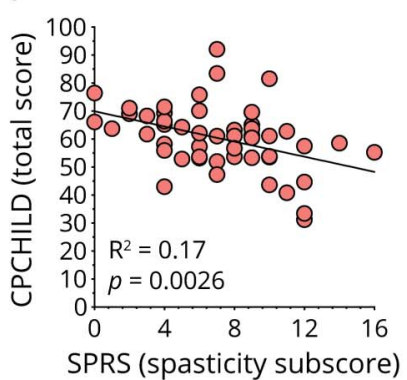

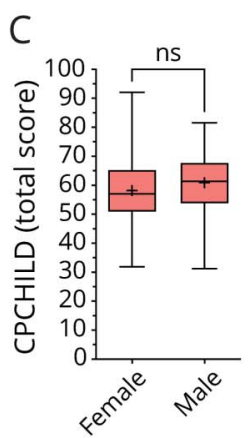
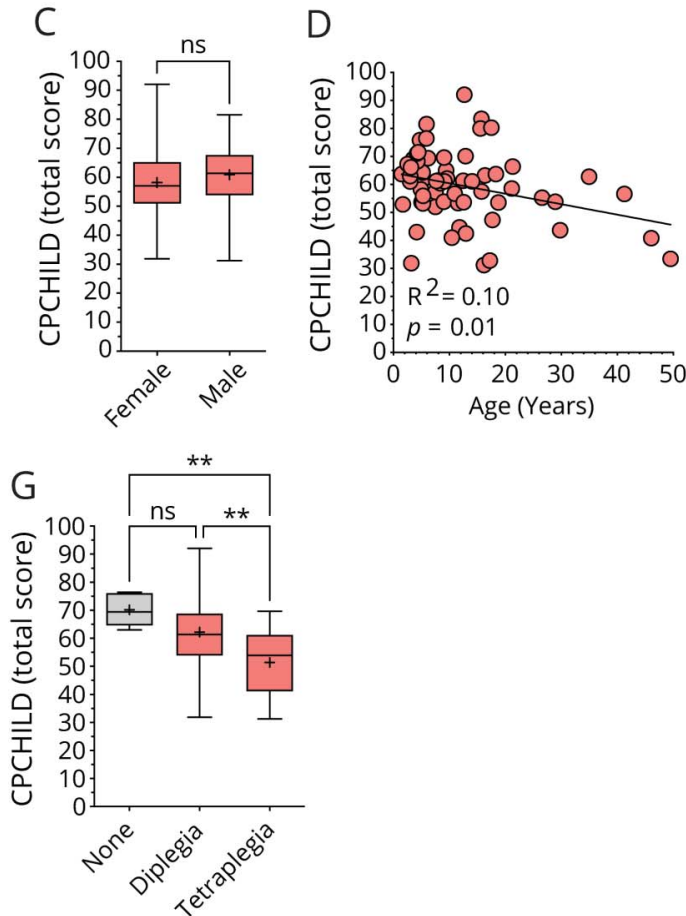

(A) No significant difference between mean scores in each of the CPCHILD sections ( 1 = activities of daily living and personal care; 2 = positioning, transferring, and mobility; 3 = comfort and emotions; 4 = communication and social interaction; and $5=$ health). (B and C) No significant differences are found in the mean CPCHILD score between subtypes of AP-4-HSP (AP4B1 = SPG47, AP4M1 = SPG50, AP4E1 = SPG51, and AP4S1 = SPG52) or female and male patients. (D-F) Lower CPCHILD scores correlate with age (Pearson correlation coefficient: $r=-0.31, p=0.01$; Spearman correlation coefficient: $r=-0.25, p=0.05$ ), higher total SPRS scores (Pearson correlation coefficient: $r=-0.52, p<0.0001$; Spearman correlation coefficient: $r=-0.55, p<0.0001$ ), and spasticity subscores (Pearson correlation coefficient: $r=-0.41, p=0.0026$; Spearman correlation coefficient: $r=-0.46, p=0.0008$ ). (E) One data point is outside the axis limits. (G) Patients with spastic tetraplegia $(n=19)$ have lower CPCHILD scores compared with patients with spastic diplegia $(n=40)$ or no spasticity $(n=5)$. Box and whisker plots in (A): Whiskers indicate 10-90 percentile. Box and whisker plots in (B, C, G): Whiskers indicate the full range (min-max). " + " denotes the mean. Significance: * $p$ $<0.05, * * p<0.01$, and $* * \star p<0.001$. AP-4-HSP = AP-4-associated hereditary spastic paraplegia; CPCHILD = Caregiver Priorities and Child Health Index of Life with Disabilities; ns = not significant; SPRS = Spastic Paraplegia Rating Scale. 
Figure 2 Correlation of Health-Related Quality of Life With Additional Symptoms and Caregiver Priorities in AP-4-Associated Hereditary Spastic Paraplegia
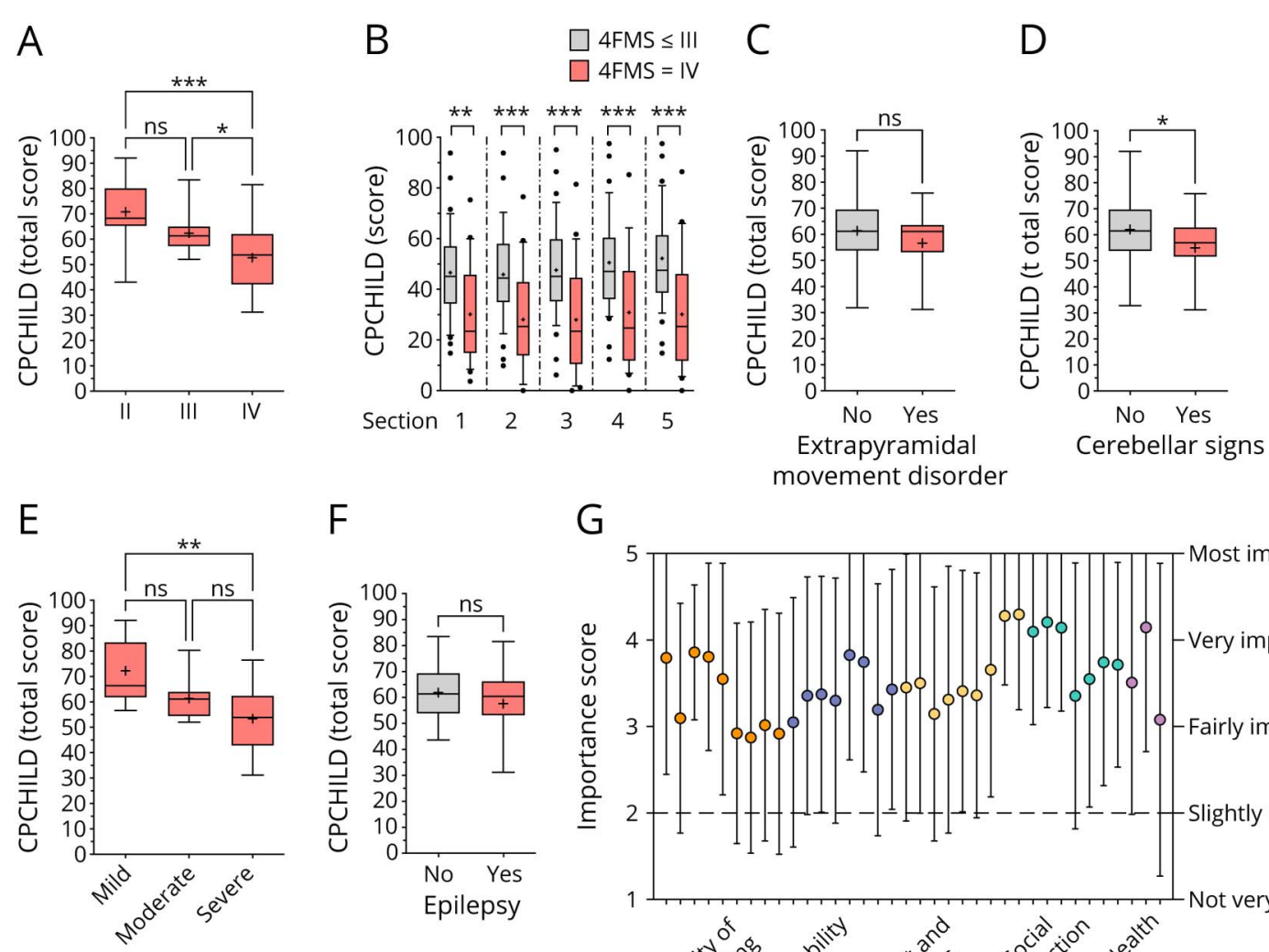

G

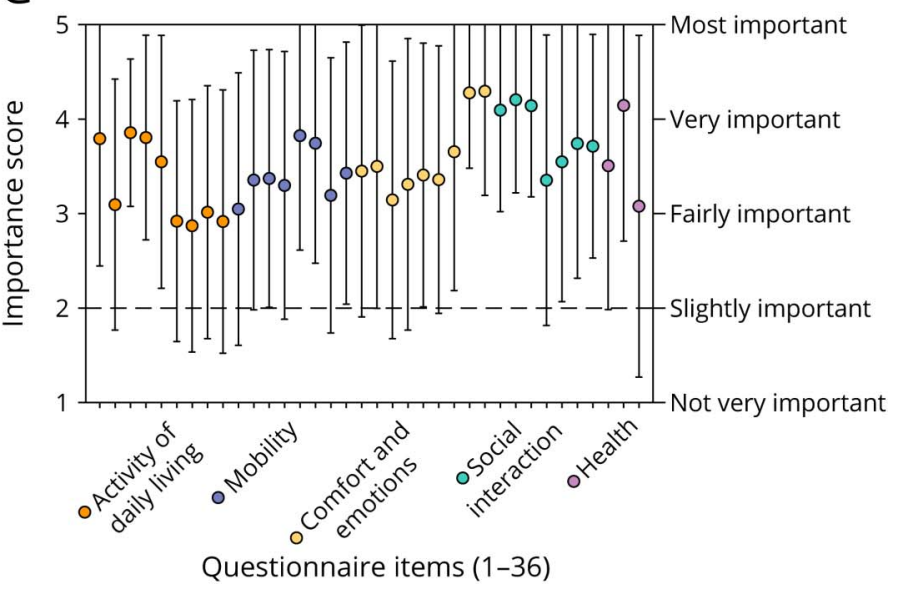

(A) Patients with an 4FMS score of IV, indicating dependence on a wheelchair $(\mathrm{n}=26)$, have lower CPCHILD scores compared with those ambulating with assistance (4FMS = III, $\mathrm{n}=26$ ) or independently (4FMS $=I I, n=9$ ). (B) Assessment of mean scores for each section of the CPCHILD shows that wheelchairdependent patients have lower scores in all domain compared with patients who do not require a wheelchair. (C and D) The presence of an extrapyramidal movement disorder (dystonia, chorea, athetosis, myoclonus, tremor, rigidity, or postural instability, $n=24$ ) did not lead to significantly lower CPCHILD scores, whereas the presence of cerebellar signs (cerebellar ataxia, dysmetria, nystagmus, or intention tremor, $n=22$ ) did. (E) The mean CPCHILD score was reduced in patients with severe intellectual disability $(n=24)$ compared with patients with mild intellectual impairment $(n=7)$. No difference was found between patients with severe and moderate intellectual disability $(n=20)$. (F) Surprisingly, the presence of epilepsy did not influence CPCHILD scores. (G) Rating of importance for each item on the CPCHILD questionnaire. No items were rated below the threshold level of importance (2.0 = slightly important). Items relating to communication and social interaction, comfort and emotions, and health were, on average, considered more important contributors to quality of life than items relating to positioning, transferring, and mobility, and personal care and activities of daily living. Box and whisker plots in (A-G): Whiskers indicate the full range (min-max). "+" denotes the mean. Significance: ${ }^{*} p<0.05,{ }^{* *} p<0.01$, and ${ }^{* *} * p<0.001$. 4FMS $=4$-stage functional mobility scale; CPCHILD = Caregiver Priorities and Child Health Index of Life with Disabilities; ns = not significant; SPRS = Spastic Paraplegia Rating Scale.

mean scores for each section and discovered that wheelchairdependent patients had significantly lower scores in all domains (Figure 2B). The presence of contractures was not associated with lower CPCHILD scores $(p=0.25)$ as was the presence of extrapyramidal movement disorders (Figure 2C). Cerebellar signs, most commonly ataxia, were associated with lower HRQoL (Figure 2D), possibly due to the fact that this is often a manifestation of advanced disease stages. ${ }^{2}$

Of interest, we found that CPCHILD scores did not discriminate between patients with moderate and severe intellectual disability, although scores were significantly lower in the group with severe intellectual impairment compared with those in the mild range (Figure $2 \mathrm{E}$ ). Surprisingly, the presence of epilepsy did not correlate with HRQoL (Figure 2F). To investigate whether this was due to the fact that seizures were well controlled on $<2$ antiepileptic drugs in the majority of patients, we explored the subgroup with medically refractory epilepsy. We did not detect a significant difference in CPCHILD scores between patients with uncontrolled epilepsy, controlled epilepsy, or no seizures at all ( $p=0.87$ and $p$ $=0.52$, respectively).

Finally, we assessed whether having 2 or more affected children would affect HRQoL, given the increased resources needed to care for multiple family members. Of interest, we did not detect any difference between CPCHILD scores in individuals from families with 1 vs multiple affected family members $(p=0.26)$.

Section 7 of the CPCHILD incorporates the caregivers' perspective on the importance of each item in the questionnaire. 
The mean importance rating for all CPCHILD items was 3.5 \pm 0.4 (SD) indicating that all items were deemed fairly important to very important (Figure $2 \mathrm{G}$ ). Items relating to (1) communication and social interaction, (2) comfort and emotions, and (3) health were considered the most important contributors to quality of life.

\section{Discussion}

Although quality of life has been assessed in adults with HSP, ${ }^{9,10}$ including as an end point in interventional trials, standardized assessments of HRQoL in children with complex hereditary spastic paraplegia are lacking. Here, we show that (1) the CPCHILD questionnaire, developed for use in children with cerebral palsy, ${ }^{4}$ can be used to assess HRQoL in patients with childhood-onset complex HSP and (2) HRQoL is impaired across the age spectrum of patients with AP-4-HSP and correlates with disease duration and motor impairment. Similar to findings in children with severe cerebral palsy (Gross Motor Function Classification System IV), ${ }^{4,8}$ we found that tetraplegia and wheelchair dependence were associated with lower CPCHILD scores. Of interest, we did not observe a correlation of HRQoL with epilepsy or a significant difference between patients with moderate or severe intellectual disability, indicating that these are less impactful contributors to HRQoL in AP-4-HSP. We speculate that the progressive nature of motor impairment in AP-4-HSP ${ }^{2}$ with associated gradual decline in the ability to participate in daily activities may explain the greater effect on HRQoL compared with the relatively static findings of intellectual impairment and epilepsy. This is being further investigated as part of a longitudinal natural history (ClinicalTrials.gov identifier: NCT04712812).

There are limitations to our study: (1) Our cohort is enriched in patients residing in countries with access to specialized health care and developmental support compared with larger cohorts. ${ }^{2}$ Future studies will need to assess whether correlations prevail in different health care settings. (2) The crosssectional nature of our study precludes a longitudinal assessment of HRQoL at the level of an individual. Prospective natural history studies will need to assess whether changes in HRQoL over time correlate with the rate of disease progression. (3) It will be important to compare results obtained with the CPCHILD questionnaire with other metrics of HRQoL designed for cerebral palsy or children and adults with other neurodisabilities.

Despite these limitations, our results establish the CPCHILD questionnaire as a metric to assess HRQoL in complex HSP. Integrating an assessment of HRQoL in the routine care of patients with AP-4-HSP may guide clinicians toward a better understanding of caregiver priorities, may inform decisionmaking about interventions, and may provide a means to assess outcomes.

\section{Acknowledgment}

The authors thank the patients and their families who participated in this study. The authors also thank $U$. Narayanan (The Hospital for Sick Children and Holland Bloorview Kids Rehabilitation Hospital, Toronto, Canada) for permission to use the CPCHILD questionnaire.

\section{Study Funding}

D. Ebrahimi-Fakhari received support from the CureAP4 Foundation, the Spastic Paraplegia Foundation, and the National Institutes of Health/NINDS (2R25NS070682). J.E. Alecu was supported by the Deutsche Forschungsgemeinschaft (DFG, German Research Foundation 270949263/GRK2162), the German National Academic Foundation, and the Max WeberProgram of the State of Bavaria. M. Sahin was supported by Boston Children's Hospital IDDRC, NIH 1U54HD090255, and the Rosamund Stone Zander Chair.

\section{Disclosure}

C. Jordan, G. Geisel, J.E. Alecu, and B. Zhang report no disclosures relevant to the manuscript. M. Sahin reports grant support from Novartis, Roche, Biogen, Astellas, Aucta, Aeovian, Bridgebio, and Quadrant Biosciences; he has served on Scientific Advisory Boards for Roche, Celgene, Regenxbio, and Takeda. D. Ebrahimi-Fakhari received an honorarium for speaking at the Movement Disorder International Congress in 2019, royalties from Cambridge University Press as an editor for "Movement Disorders and Inherited Metabolic Disorders," a consulting fee from Alcimed Inc., and reports research funding through a joint research agreement with Astellas Pharmaceuticals Inc. Go to Neurology.org/NG for full disclosures.

\section{Publication History}

Received by Neurology: Genetics January 5, 2021. Accepted in final form April 23, 2021.

\section{Appendix Authors}

\begin{tabular}{lll}
\hline Name & Location & Contribution \\
\hline $\begin{array}{l}\text { Catherine Jordan, } \\
\text { BA }\end{array}$ & $\begin{array}{l}\text { Boston } \\
\text { Children's } \\
\text { Hospital, MA }\end{array}$ & $\begin{array}{l}\text { Acquisition of data, analyzed the } \\
\text { data, and revised the article }\end{array}$ \\
\hline $\begin{array}{l}\text { Gregory Geisel, } \\
\text { BS }\end{array}$ & $\begin{array}{l}\text { Boston } \\
\text { Children's } \\
\text { Hospital, MA }\end{array}$ & $\begin{array}{l}\text { Acquisition of data and revised the } \\
\text { article }\end{array}$ \\
\hline $\begin{array}{l}\text { Julian E. Alecu, } \\
\text { cand. med. }\end{array}$ & $\begin{array}{l}\text { Boston } \\
\text { Children's } \\
\text { Hospital, MA }\end{array}$ & $\begin{array}{l}\text { Acquisition of data and revised the } \\
\text { article }\end{array}$ \\
\hline $\begin{array}{l}\text { Bo Zhang, PhD } \\
\text { Boston } \\
\text { Children's } \\
\text { Hospital, MA }\end{array}$ & $\begin{array}{l}\text { Analyzed the data and revised the } \\
\text { article }\end{array}$ \\
\hline $\begin{array}{l}\text { Mustafa Sahin, } \\
\text { MD, PhD }\end{array}$ & $\begin{array}{l}\text { Boston } \\
\text { Children's } \\
\text { Hospital, MA }\end{array}$ & $\begin{array}{l}\text { Design and conceptualized study } \\
\text { and revised the article }\end{array}$ \\
\hline $\begin{array}{l}\text { Darius Ebrahimi- } \\
\text { Fakhari, MD, PhD }\end{array}$ & $\begin{array}{l}\text { Boston } \\
\text { Children's } \\
\text { Hospital, MA }\end{array}$ & $\begin{array}{l}\text { Design and conceptualized study, } \\
\text { analyzed the data, and drafted and } \\
\text { revised the article }\end{array}$ \\
\hline
\end{tabular}




\section{References}

1. Ebrahimi-Fakhari D, Behne R, Davies AK, Hirst J. AP-4-associated hereditary spastic paraplegia. In: Adam MP, Ardinger HH, Pagon RA, et al, eds. GeneReviews. University of Washington, Seattle; 2018.

2. Ebrahimi-Fakhari D, Teinert J, Behne R, et al. Defining the clinical, molecular and imaging spectrum of adaptor protein complex 4-associated hereditary spastic paraplegia. Brain. 2020;143(10):2929-2944.

3. Ebrahimi-Fakhari D, Cheng $\mathrm{C}$, Dies $\mathrm{K}$, et al. Clinical and genetic characterization of AP4B1-associated SPG47. Am J Med Genet A. 2018;176(2):311-318.

4. Narayanan UG, Fehlings D, Weir S, Knights S, Kiran S, Campbell K. Initial development and validation of the Caregiver Priorities and Child Health Index of Life with Disabilities (CPCHILD). Dev Med Child Neurol. 2006;48(10):804-812.

5. Schule R, Holland-Letz T, Klimpe S, et al. The Spastic Paraplegia Rating Scale (SPRS): a reliable and valid measure of disease severity. Neurology. 2006;67(3):430-434.
6. Karle KN, Schule R, Klebe S, et al. Electrophysiological characterisation of motor and sensory tracts in patients with hereditary spastic paraplegia (HSP). Orphanet J Rare Dis. $2013 ; 8: 158$.

7. Vargus-Adams J. Health-related quality of life in childhood cerebral palsy. Arch Phys Med Rehabil. 2005;86(5):940-945.

8. Jung $\mathrm{NH}$, Brix $\mathrm{O}$, Bernius $\mathrm{P}$, et al. German translation of the caregiver priorities and child health index of life with disabilities questionnaire: test-retest reliability and correlation with gross motor function in children with cerebral palsy. Neuropediatrics. 2014;45(5):289-293.

9. Klimpe S, Schule R, Kassubek J, et al. Disease severity affects quality of life of hereditary spastic paraplegia patients. Eur J Neurol. 2012;19(1):168-171.

10. Braschinsky M, Rannikmae K, Krikmann U, et al. Health-related quality of life in patients with hereditary spastic paraplegia in Estonia. Spinal Cord. 2011;49(2): 175-181. 


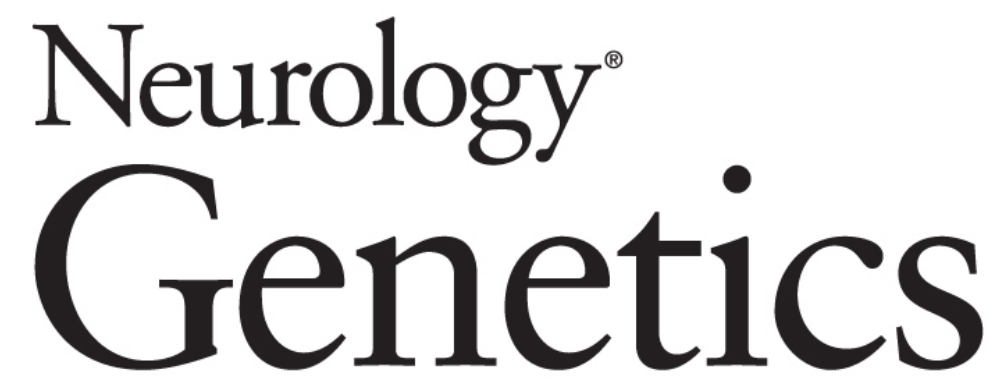

Disease Severity and Motor Impairment Correlate With Health-Related Quality of Life in AP-4-Associated Hereditary Spastic Paraplegia

Catherine Jordan, Gregory Geisel, Julian E. Alecu, et al. Neurol Genet 2021;7;

DOI 10.1212/NXG.0000000000000605

This information is current as of July 20, 2021

Neurol Genet is an official journal of the American Academy of Neurology. Published since April 2015, it is an open-access, online-only, continuous publication journal. Copyright Copyright (C 2021 The Author(s). Published by Wolters Kluwer Health, Inc. on behalf of the American Academy of Neurology.. All rights reserved. Online ISSN: 2376-7839.

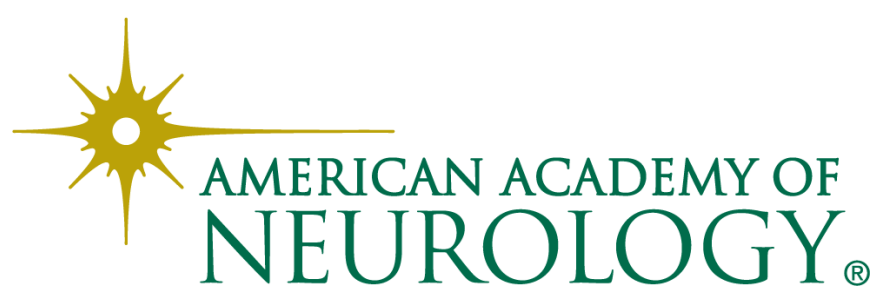




\section{Updated Information \& Services}

References

Citations

Subspecialty Collections

Permissions \& Licensing

Reprints including high resolution figures, can be found at: http://ng.neurology.org/content/7/4/e605.full.html

This article cites 9 articles, 0 of which you can access for free at: http://ng.neurology.org/content/7/4/e605.full.html\#\#ref-list-1

This article has been cited by 1 HighWire-hosted articles: http://ng.neurology.org/content/7/4/e605.full.html\#\#otherarticles

This article, along with others on similar topics, appears in the following collection(s):

\section{All Genetics}

http://ng.neurology.org//cgi/collection/all_genetics

All Movement Disorders

http://ng.neurology.org//cgi/collection/all_movement_disorders

\section{All Pediatric}

http://ng.neurology.org//cgi/collection/all_pediatric

Spastic paraplegia

http://ng.neurology.org//cgi/collection/spastic_paraplegia

Information about reproducing this article in parts (figures,tables) or in its entirety can be found online at:

http://ng.neurology.org/misc/about.xhtml\#permissions

Information about ordering reprints can be found online: http://ng.neurology.org/misc/addir.xhtml\#reprintsus

Neurol Genet is an official journal of the American Academy of Neurology. Published since April 2015, it is an open-access, online-only, continuous publication journal. Copyright Copyright $\odot 2021$ The Author(s). Published by Wolters Kluwer Health, Inc. on behalf of the American Academy of Neurology.. All rights reserved. Online ISSN: 2376-7839.

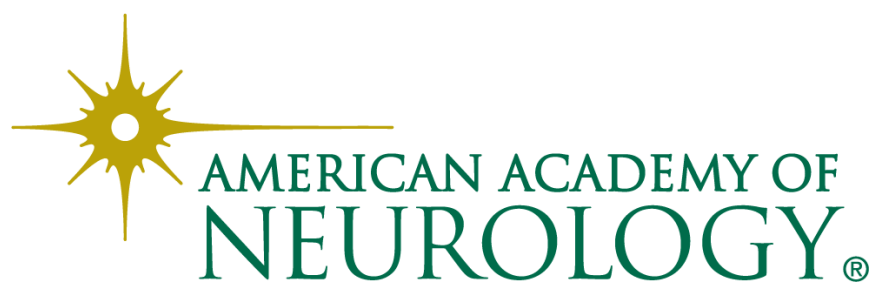

